\title{
Results of a 60 second foot screening for patients with diabetes conducted on the 2011 world diabetes day
}

\author{
Prisca Olabisi Adejumo ${ }^{1}$, Ade F. Adeniyi ${ }^{2}$, Adesoji A. Fasanmade ${ }^{3}$ \\ 1. Department of Nursing, College of Medicine, University of I badan, Nigeria. 2. Department of Physiotherapy, College of \\ Medicine, University of I badan, Nigeria. 3. Department of Medicine, College of Medicine, University of I badan, Nigeria
}

Correspondence: Dr. Prisca Olabisi Adejumo. Address: Department of Nursing, College of Medicine, University of Ibadan, Nigeria. E-mail: bisiandbayo@yahoo.com.

Received: November 27, 2012

Accepted: January 8, $2013 \quad$ Online Published: March 11, 2013

DOI : 10.5430/jnep.v3n9p114

URL: http://dx.doi.org/10.5430/jnep.v3n9p114

\section{Abstract}

Background: One of the disabling complications of diabetes is foot ulcer and a major way of preventing this complication is access to prompt and regular foot screening. However, because of many competing health demands of the patients, foot screening does not receive adequate attention and many do not get to be screened early enough especially in the developing countries like Nigeria. This study applied a foot screening protocol on diabetic patients who converged at the 2011 annual World Diabetes Day held in Ibadan, Nigeria.

Methods: This study was a one-day cross-sectional survey. Patients were screened for the risk of diabetic foot using the 60 Second Diabetic Foot Screen. The screening covered aspects of past histories of foot ulcers, circulatory disorders, foot deformities and peripheral neuropathy. Data were analysed using descriptive and inferential statistics at $p=0.05$.

Results: Seventy-five patients with mean age of $60.0 \pm 12.6$ years participated in the screening. Foot deformities $(12 \%)$, thick planter calluses $(13.3 \%)$, maceration between toes (16\%) and peripheral neuropathy $(21.3 \%)$ were seen among the patients. Overall, $29.2 \%$ of the patients presented with at least a risk for the development of foot ulcer and only random blood glucose was significantly associated $(p=0.018)$ with peripheral neuropathy.

Conclusions: This study has shown that about one out of every three of the patients with diabetes presented with at least a risk for the development of foot ulcer. This study has also demonstrated that foot screening carried out on special days like the World Diabetes Days may serve as an opportunity to provide at least once in a year foot screening access to patients with diabetes.

\section{Key words}

Diabetes, Foot ulcer, Peripheral neuropathy, Foot deformities

\section{Introduction}

Lower extremity problems represent the most common source of complications and hospitalization in the diabetic population ${ }^{[1]}$. Previous studies of persons with diabetes have identified neuropathy (loss of protective sensation), peripheral vascular disease, prior foot ulcer, or previous amputation as risk factors for developing a foot ulcer ${ }^{[2]}$. Although optimal diabetes control reduces chronic complications, actual provision of diabetes care frequently falls short of accepted guidelines ${ }^{[3]}$. Estimating rates of, and risk factors for diabetes complications is therefore important for planning health 
care effectively, improve understanding of disease natural history, and target therapeutic interventions for patients with diabetes ${ }^{[4]}$.

Foot screening is an important process towards the reduction of foot complications among patients with diabetes. Regular foot examinations are essential for all diabetic patients because the circulatory and neuropathic sequel of diabetes can turn minor breakdowns into severe ulcerations that lead to amputation ${ }^{[5,6]}$. The promptness and frequency of screening that is required by the patients is however not readily available to the patients, especially from a developing country like Nigeria, creating a "gap" between what the patient needs and what is available to the patient. This is not necessarily because the skilled personnel are not available but because the few health care personnel are usually overwhelmed by the workload due to the relatively large turnout of patients with diabetes. This may lead to an insufficient attention to the foot because of some other pressing needs of the patients with diabetes. Although it is generally agreed that there is a need to screen the feet of persons with diabetes ${ }^{[6]}$ this is usually challenging because of the lack of standardized diabetic foot examination in some settings and because it can be perceived as time consuming ${ }^{[2]}$. This often relegates foot screening to the background among a group of procedures to take the diabetic patient through. For instance, a generalized documentation form is difficult to complete with 180 patients processed over a daylong clinic with only 2 to 5 medical personnel ${ }^{[2]}$. It is however reported that a high-risk diabetic foot can be identified with a simplified screening instrument (the 60 Second Foot Screen), thereby preventing subsequent foot ulcers ${ }^{[2,7]}$. The World Diabetes Day therefore served as an opportunity to bridge this healthcare gap by making foot screening available to the patients and to fairly estimate the burden of the problem among a converging sample of patients from different healthcare backgrounds.

\section{Methodology}

\subsection{The World Diabetes Day and the participants}

This study was conducted during the 2011 celebration of the World Diabetes Day. The World Diabetes Day is marked annually to raise global awareness of diabetes - its escalating rates around the world and how to prevent the illness in most cases. Started by the International Diabetes Federation and the World Health Organization, the Day is celebrated on 14 November to mark the birthday of Frederick Banting who, along with Charles Best, was instrumental in the discovery of insulin in 1922, a life-saving treatment for diabetes patients ${ }^{[8]}$. Every year, the Diabetes Association of Nigeria (an umbrella association of patients with diabetes seen at different hospitals) also commemorates the Day by organizing public lectures and free diabetes screening for the general populace including those with known and unknown diabetes. This is usually done in an informal setting, at a venue determined by the association. The association makes announcement on many information media inviting people to come for the programme. During the 2011 celebration, held at the main hall of a secondary school in Ibadan, Nigeria, the programme had in attendance both diabetic and non diabetic patients. For the 2011 event, the participants received foot screening in addition to the diabetes screening and lectures. However, for the purpose of this study, only the foot screening data of those who were known to be patients with diabetes, who were at the same time members of the Diabetes Association of Nigeria were included in the analysis of this study. This was to minimize the possibility of recruiting into the study persons who were not true diabetic patients since single random blood glucose may not be sufficient to do the diagnosis. The known diabetic patients were earlier informed about the screening at their last clinic appointment before the World Diabetes Day. All interested persons, with known or unknown diabetes who attended the ceremony received the lecture that was given to the general public; and most of them, except those who declined went through the screening.

\subsection{The 60 second foot screen}

This instrument is a 60 second foot screening tool developed by Sibbald et al ${ }^{[7]}$. It is modified and similar to the Inlow's 60 Second Diabetic Foot Screen ${ }^{[9]}$. The instrument was selected because it is a simplified tool that did not require a calculation for risk status and could be administered in less than 1 minute. One minute was chosen as a reasonable time interval that was convenient and easy to remember ${ }^{[2]}$. Additionally, it was chosen because it has the ability to assess many 
foot lesions. It assesses a number of domains including previous history considering histories of foot ulcer and amputations, physical examinations (pedal pulses, musculoskeletal problems etc), foot lesions and skin problems and it also documents the Semmes-Weinstein's monofilament (SWM) examination for peripheral neuropathy ${ }^{[7]}$. Responses are not presented in numerical values but as YES or NO. Just a single YES implies a risk for foot ulcer, infections and/or amputation and the patients should be referred to foot clinic. If all responses are NO, then the patient should be seen for re-examination in one year ${ }^{[7]}$. The guidelines recommending foot examination including inspection for foot abnormalities, palpation of the pulse, and the use of a 10-g SWM test served as evidence base for the criteria listed in the 60-second tool $^{[2]}$. The screening test identifies the high-risk diabetic foot status. It has been designed to identify any "YES" item on the feet as high-risk foot. If a high-risk foot is identified, there is a need for a referral or treatment ${ }^{[2]}$. The instrument has been applied previously in the screening of 1266 patients in Guyana, South America ${ }^{[10]}$.

\subsection{The foot screening exercise}

After the various lectures presented by different health professionals on various aspects of healthcare for people with diabetes, each of the participants took time to go through the foot screening exercise. The foot screening was conducted by experts including endocrinologist, nurses and a physiotherapist who are all clinical experts and researchers in the field of diabetes. They have also received training including the use of the 60 Second Foot Screen and have also been resource persons at foot screening training workshops for healthcare workers. The patients had been informed of the need to undergo regular foot screening and they were each allowed to make their choices on whether they wanted to participate in the screening or not. The tests were basically tailored towards the assessment of risk for developing diabetic foot. Risk in this sense refers to factors that have the potential to cause a diabetic foot. The test was conducted based on the items listed on the 60 Second Foot Screen ${ }^{[7]}$. In addition, the participants also had their body weight and blood sugar measured using the weighing scale and the blood sugar monitor respectively. Participants' age and duration of diagnosis were also recorded for each patient. All activities were carried out in three stations within the hall. The first station was for weight and random blood glucose assessment and demographics including age, sex and duration of diagnosis of diabetes.

The second station was for foot examination using the 60 Second Foot Screening tool. At this station, histories were taken about previous ulcer, previous amputation and assessments were made for any structural deformities on the foot such as hallux valgus/varus, pes planus, Charcot's foot, hammer toes etc. Pedal pulses at the dorsalis paedis and posterior tibial arteries were assessed. Any fixed joint on the ankle or large toes were also assessed. The patients were checked for any foot lesions including active ulcer, ingrown toe nail, callus formation, blisters, fissures (linear cracks) etc. Finally, the patients were assessed for peripheral neuropathy using the 10g SWM (manufactured by Diabetik Foot Care, India) on both feet. Ten points were tested on each foot with at least 4 negative responses on the perception of the monofilament taken as confirmation of the peripheral neuropathy on that foot ${ }^{[6,7]}$. The third station was the patient education section. Diabetes is a chronic illness that requires continuing medical care and ongoing patient self-management education and support to prevent acute complications and to reduce the risk of long-term complications ${ }^{[6]}$. Here, the patients were educated based on the observation made on each of the patient's questionnaire. Those who were identified by the 60 Second Foot Screen as having a risk for diabetic foot were provided a focused education on foot care and the need to be able to check their own foot regularly and to seek help as soon as the need arises. A YES for at least a single item assessed on the 60 Second Foot Screen in the second station implied an increased risk of foot ulcer, infection or amputation and the patients were educated on all of these. They were also provided with information on basic tips for the care of their feet. This covered aspects of supportive and comfortable shoes, and cleaning, moisturizing and how to examine their feet every day ${ }^{[2,5]}$. They were also advised to seek further help for foot care. Those who did not have any risk were asked to go through the screening process again in a maximum of 1 year's time.

A number of challenges were met during the screening exercise. First, the process was a field screening procedure and it was to be held only on that day. This created a number of difficulties. Because of the short time frame, we were not able to have all the participants screened. Additionally, some of the participants did not undergo all the screening on the 60 Second Foot Screening tool. This was because some of the patients were in a hurry to go to the next station and were not patient enough to complete all the tests. Others could not provide responses to questions concerning previous history of 
foot lesions. In addition, some of the patients were distracted and could not pull through the full screening process because it was an "open field screening" and the fact that the venue served as a spot for some of the patients to socialize. For instance, being an annual event, the assembly serves as the only convergent forum where members of the patients' Diabetes Association of Nigeria meet one another again and that caused some level of distraction. The authors adopted the approach of not labeling the observation made on each participant as either YES or NO when there were doubts on the true situation of the patient's presentation or when the patient could not be tested for that particular aspect. Such cases were labeled as "could not be determined".

\subsection{Data analysis}

The data were analysed using descriptive statistics and results presented in tables and charts. The data were further analysed using Chi squared test to determine the association between result of SWM test and some demographic and clinical variables. Analysis was conducted using SPSS Version 16 (SPSS Inc, Chicago, IL, U.S.A.). Level of significance was set at $p=0.05$.

\section{Results}

Seventy-five patients (31 (41.3\%) males and 44 (58.7\%) females) participated in the 60 seconds screening test. This represents a $73.5 \%$ response rate out of the 102 patients who were members of the Diabetes Association of Nigeria who were in attendance. The mean age of the patients was $60.0 \pm 12.6$ years (range $27-89$ ) while the mean years with diabetes diagnosis was $8.95 \pm 6.9$ years (range $0-50$ ). More than half $(54 \%)$ of the patients were within the age range of $\geq 61$ years (see Figure 1). Only 13\% of the patients have had diabetes for $\geq 20$ years (see Figure 2). The mean random blood glucose level of patients was $159.1 \pm 108.2 \mathrm{mg} / \mathrm{DL}$ (range $64-523$ ). Only $6.7 \%$ had a random blood glucose level in the range of $70-100$ (see Figure 3). The mean body weight of patients was $68.8 \pm 16.6 \mathrm{~kg}$ (range $6.2-105.0$ ). The percentage of patients with $\geq 80 \mathrm{~kg}$ body weight was 13.3 (see Figure 4 ).

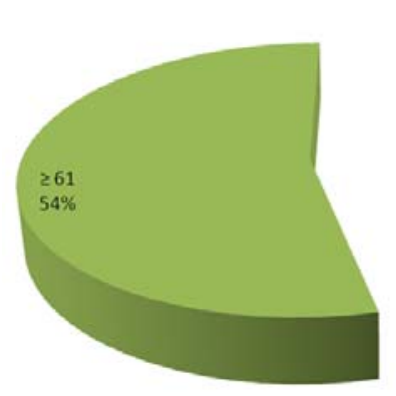

Figure 1. Age of patients

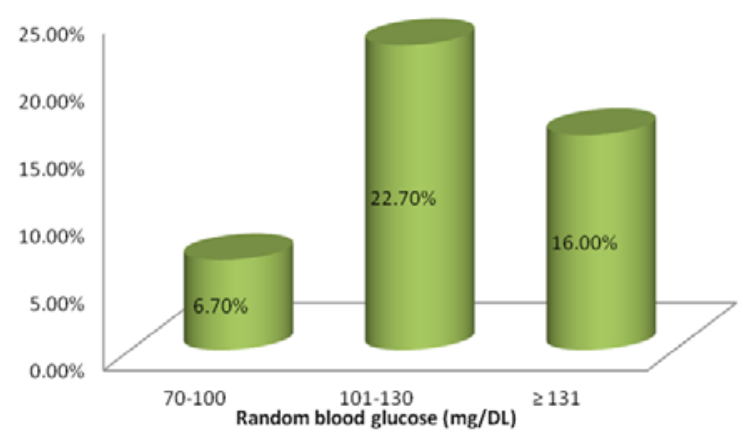

Figure 3. Random blood glucose of patients

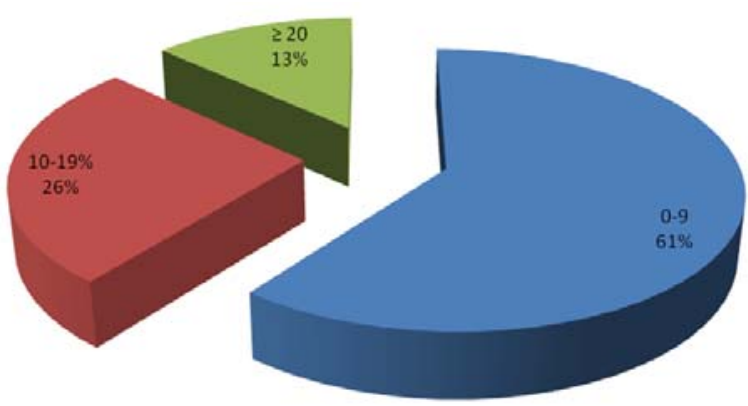

Figure 2. Patient years with diabetes diagnosis

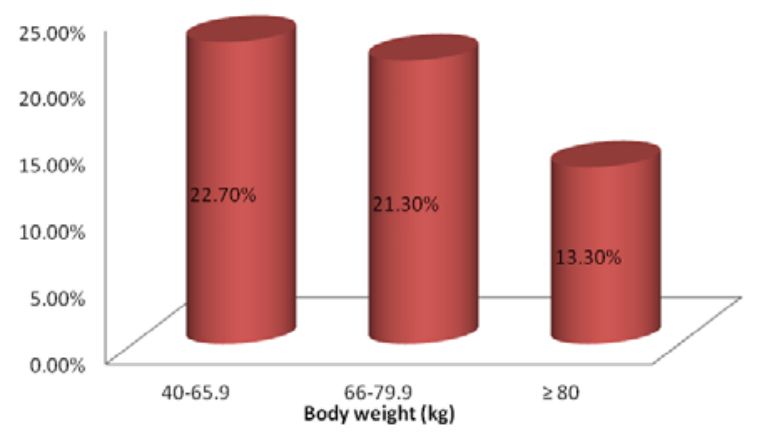

Figure 4. Body weight of patients

The value of variables on the 60 Second Foot Screen is listed in table 1. The proportion of each assessment that could not be made for each of the items is also presented as "could not be determined" in the table. If a test is positive, it is marked as 
YES and marked as NO if it is negative. At least a YES for any of the tests implies a risk for developing diabetes foot. All NOs on the instrument indicates that the person has to be re-assessed in 1 year's time. None of the patients presented with any amputation, fixed toe or ankle joint, active ulcer, ingrown toe nail and blisters. However, maceration between toes though not included as part of the 60 Second Foot Screen was documented because it was found in $12(16 \%)$ of the patients. On further examination of the patients' feet using the SWM, $20.0 \%$ and $21.3 \%$ of the patients had a positive result for high risk of diabetic foot on the right and left feet respectively scoring $\geq 4 / 10$ negatives (see Table 1 ). One person $(1.3 \%)$ presented with a history of previous ulcer. Based on the number of individuals accumulating a YES for any of the items on the questionnaire, a total of $29.2 \%$ accumulated at least a YES. We conducted a Chi squared test to find if any association existed between the SWM test and each of age, duration of diabetes diagnosis, random blood glucose and body weight of the patients. Of all these variables, only the random blood glucose was significantly associated $(p=0.018)$ with SWM reading (see Table 2).

Table 1. Descriptive results of the foot screening exercise

\begin{tabular}{|c|c|c|c|}
\hline Variable & Response & Frequency & Percentage \\
\hline \multirow{3}{*}{ Previous ulcer } & Yes & 1 & 1.3 \\
\hline & No & 67 & 89.3 \\
\hline & Could not be determined & 7 & 9.3 \\
\hline \multirow{3}{*}{ Previous amputation } & Yes & 0 & 0.0 \\
\hline & No & 68 & 90.7 \\
\hline & Could not be determined & 7 & 9.3 \\
\hline \multirow{3}{*}{ Deformity } & Yes & 9 & 12.0 \\
\hline & No & 59 & 78.7 \\
\hline & Could not be determined & 7 & 9.3 \\
\hline \multirow{3}{*}{ Pedal pulses are absent (dorsalis pedis or posterior tibal) } & Yes & 1 & 1.3 \\
\hline & No & 65 & 86.7 \\
\hline & Could not be determined & 9 & 12.0 \\
\hline \multirow{3}{*}{ Fixed joint (no movement ankle) } & Yes & 0 & 0.0 \\
\hline & No & 68 & 90.7 \\
\hline & Could not be determined & 7 & 9.3 \\
\hline \multirow{3}{*}{ Fixed joint (no movement large toe) } & Yes & 0 & 0.0 \\
\hline & No & 68 & 90.7 \\
\hline & Could not be determined & 7 & 9.3 \\
\hline \multirow{3}{*}{ Active ulcer } & Yes & 0 & 0.0 \\
\hline & No & 68 & 90.7 \\
\hline & Could not be determined & 7 & 9.3 \\
\hline \multirow{3}{*}{ Ingrown toe nail } & Yes & 0 & 0.0 \\
\hline & No & 68 & 90.7 \\
\hline & Could not be determined & 7 & 9.3 \\
\hline \multirow{3}{*}{ Calluses (thick plantar skin) } & Yes & 10 & 13.3 \\
\hline & No & 58 & 77.3 \\
\hline & Could not be determined & 7 & 9.3 \\
\hline \multirow{3}{*}{ Blisters } & Yes & 0 & 0.0 \\
\hline & No & 68 & 90.7 \\
\hline & Could not be determined & 7 & 9.3 \\
\hline \multirow{3}{*}{ Fissure (linear crack) } & Yes & 4 & 5.3 \\
\hline & No & 64 & 85.3 \\
\hline & Could not be determined & 7 & 9.3 \\
\hline \multirow{3}{*}{ Monofilament exam (right) } & Yes $(>4 / 10$ neg $)$ & 15 & 20.0 \\
\hline & No $(<4 / 10 \mathrm{neg})$ & 56 & 74.7 \\
\hline & Could not be determined & 4 & 5.3 \\
\hline \multirow{3}{*}{ Monofilament exam (left) } & Yes $(>4 / 10$ neg) & 16 & 21.3 \\
\hline & No $(<4 / 10$ neg) & 55 & 73.3 \\
\hline & Could not be determined & 4 & 5.3 \\
\hline \multirow{3}{*}{ *Maceration } & Yes & 12 & 16.0 \\
\hline & No & 62 & 82.7 \\
\hline & Could not be determined & 1 & 1.3 \\
\hline
\end{tabular}

Note. * Maceration is not part of the 60 Second Foot Screen. It only featured because it was seen among some of the patients 
Table 2. Associations between selected variables and monofilament examination results

\begin{tabular}{|c|c|c|c|c|c|}
\hline & & & Yes (>4/10 neg) & No (<4/10 neg) & $p$-value \\
\hline \multirow{6}{*}{ Age of patients } & \multirow{3}{*}{$\begin{array}{l}\text { Monofilament } \\
\text { exam (left) }\end{array}$} & $20-44$ & $0(0.0)$ & $8(13.1)$ & \multirow{3}{*}{0.082} \\
\hline & & $45-60$ & $3(4.9)$ & $15(24.6)$ & \\
\hline & & $\geq 61$ & $12(19.7)$ & $23(37.7)$ & \\
\hline & \multirow{3}{*}{$\begin{array}{l}\text { Monofilament } \\
\text { exam (right) }\end{array}$} & $20-44$ & $0(0.0)$ & $8(13.1)$ & \multirow{3}{*}{0.122} \\
\hline & & $45-60$ & $3(4.9)$ & $15(24.6)$ & \\
\hline & & $\geq 61$ & $11(18.0)$ & $24(39.3)$ & \\
\hline \multirow{6}{*}{$\begin{array}{l}\text { Number of years with } \\
\text { diabetes }\end{array}$} & \multirow{3}{*}{$\begin{array}{l}\text { Monofilament } \\
\text { exam (right) }\end{array}$} & $0-9$ & $5(7.0)$ & $16(22.5)$ & \multirow{3}{*}{0.090} \\
\hline & & $10-19$ & $2(2.8)$ & $7(9.9)$ & \\
\hline & & $\geq 20$ & $1(1.4)$ & $4(5.6)$ & \\
\hline & \multirow{3}{*}{$\begin{array}{l}\text { Monofilament } \\
\text { exam (left) }\end{array}$} & $0-9$ & $4(5.6)$ & $17(23.9)$ & \multirow{3}{*}{0.983} \\
\hline & & $10-19$ & $5(7.0)$ & $4(5.6)$ & \\
\hline & & $\geq 20$ & $1(1.4)$ & $4(5.9)$ & \\
\hline \multirow{6}{*}{ Random blood glucose } & \multirow{3}{*}{$\begin{array}{l}\text { Monofilament } \\
\text { exam (right) }\end{array}$} & $70-100$ & $0(0.0)$ & $5(14.7)$ & \multirow{3}{*}{$0.018^{*}$} \\
\hline & & $101-130$ & $3(8.8)$ & $14(41.2)$ & \\
\hline & & $\geq 131$ & $7(20.6)$ & $5(14.7)$ & \\
\hline & \multirow{3}{*}{$\begin{array}{l}\text { Monofilament } \\
\text { exam (left) }\end{array}$} & $70-100$ & $0(0.0)$ & $5(14.7)$ & \multirow{3}{*}{0.053} \\
\hline & & $101-130$ & $3(8.8)$ & $14(41.2)$ & \\
\hline & & $\geq 131$ & $6(17.6)$ & $6(17.6)$ & \\
\hline \multirow{6}{*}{ Body weight of patients } & \multirow{3}{*}{$\begin{array}{l}\text { Monofilament } \\
\text { exam (right) }\end{array}$} & $6.5-65.9$ & $3(7.3)$ & $13(31.7)$ & \multirow{3}{*}{0.083} \\
\hline & & $66-79.9$ & $7(17.1)$ & $8(19.5)$ & \\
\hline & & $\geq 80$ & $1(2.4)$ & $9(22.0)$ & \\
\hline & \multirow{3}{*}{$\begin{array}{l}\text { Monofilament } \\
\text { exam (left) }\end{array}$} & $6.5-65.9$ & $4(9.8)$ & $12(29.3)$ & \multirow{3}{*}{0.247} \\
\hline & & $66-79.9$ & $6(14.6)$ & $9(22.0)$ & \\
\hline & & $\geq 80$ & $1(2.4)$ & $9(22.0)$ & \\
\hline
\end{tabular}

*Significant at $p<0.05$

\section{Discussion}

The results of this study are based on the data from the assessment of patients with diabetes obtained on a single day field screening of the patients during the 2011 commemoration of the World Diabetes Day. The main findings from the one-day foot screening are 1) of the lesions listed on the 60 Second Foot Screen, thick planter callus had the highest prevalence $(13.3 \%)$ while foot deformities was seen in $12 \%$ of the patients, 2 ) at least one out of five of the patients had a positive test on the SMW implying a peripheral neuropathy, 3) maceration between the toes was found in $16 \%$ of the patients and 4) about one out of three of the patients with diabetes presented with a risk of infection, foot ulcer or amputation based on score of at least a YES on the foot screen.

There was a sizeable prevalence of planter calluses and foot deformities among the patients. This may not be entirely surprising in view of the fact that they are diabetic patients who may have had some period of peripheral neuropathy considering the fact that the mean years of diabetes for the patients was close to a decade. The prevalence of planter calluses could have been due to a long duration of repetitive pressure on the sole of the foot as a result of improper foot wear or as a result of asymmetry in the weight distributed on the feet, an outcome that could also accompany foot deformities. A trend toward increased pressure with increasing numbers of foot deformities has been reported ${ }^{[11]}$. We also discovered that prevalence of maceration within the toes was quite high. Although this is not listed as part of the 60 Second Foot Screen, the fact that it was quite prevalent makes it important for it to be discussed. Maceration may stem from the combination of pressure between the feet, heat and moisture. This is of serious implication for the health of the foot because as it continues to break down, it could be a convenient atmosphere for infection to thrive with its attendant complications ${ }^{[12]}$. 
The SWM test that was carried out on the patients' feet revealed that about one out of five of them had peripheral neuropathy. Reported prevalence estimates of peripheral neuropathy (or diabetic polyneuropathy) vary, in part as a result of different sampling methods and differing diagnostic criteria ${ }^{[13]}$. In a previous study ${ }^{[14]}, 12.5 \%$ reported peripheral insensate neuropathy with age- and race-adjusted prevalence being $21.2 \%$ among persons with diabetes while in another study, sensory neuropathy with loss of protective sensation was present in $27.1 \%$ of the patients ${ }^{[15]}$. The result of the studies though conducted in different settings from our own was quite similar to our findings. This may be because our patients also had some similar characteristics. For instance, the duration of diabetes was similar with that of the study, reporting mean duration of diabetes among persons with diabetes as 11.8 years and a median duration 7 years. The prevalence of peripheral insensate neuropathy which increases with age among persons with diabetes has been reported variously, ranging from $22.2 \%$ among those aged $65-69$ years to $45.5 \%$ percent among those aged 85 years or more ${ }^{[14,16-18]}$. Apparently, peripheral neuropathy could be linked with advancing age and duration of diabetes as reported by these studies. It could also be linked with poor glycaemic control among these patients as seen from the result of this current study. Deteriorating levels of glycaemic control and an increased duration of diabetes have earlier been associated with increasing likelihood of peripheral neuropathy ${ }^{[13]}$. Although peripheral neuropathy on the right foot was significantly associated with random blood glucose, no significant influence of age, duration of diabetes diagnosis and body weight on the peripheral neuropathy of the patients was observed. The reason for the significant association of peripheral neuropathy of only one foot with the random blood glucose is not known, but it may be because of the difference of one YES count between the result obtained for the right and the left feet. However, more importantly, it should be noted that the association may not be quite representative because of the casual nature of the random blood glucose.

Overall, based on the outcome of the 60 Second Foot Screen, it was discovered that close to one out of three patients with diabetes presented with a risk of foot ulcer. This is based on the fact that these individuals had presented with at least one positive sign of disorder on the 60 Second Foot Screen. The disorders that qualified them for this categorization include presentations of maceration, thick planter callus, fissures, previous history of amputation and peripheral neuropathy. The risk of ulcers or amputations has been shown to increase in people who have the following risk factors: previous amputation, past foot ulcer history, peripheral neuropathy, foot deformity, peripheral vascular disease, poor glycaemic control and cigarette smoking ${ }^{[6]}$.

This study appears casual but, it has clinical significance for both the healthcare providers and the patients with diabetes. For the healthcare providers, it has provided further basis for screening of the patients and for the patients, it has intimated them with the need to request for foot screening from time to time. For instance, Sibbald et al. ${ }^{[2]}$ realized that many patients with diabetes had open foot ulcers, blisters, fissures, or ingrown toenails, which increase the risk of secondary bacterial infections, but the patients were often not aware of these foot abnormalities. It is believed that sustenance of this type of free foot screening on special days like the World Diabetes Day will go a long way in identifying the risks of foot ulcers early enough to reduce the burden of amputations arising from late or advanced stage of presentation of foot lesions.

Because of the setting of this study and because of some incomplete screening tests, the results obtained have some limitations and may not precisely represent the population of patients with diabetes in Ibadan. We however believe that the observations made from this study could only be the minimum, indicating that the problems may be more than what we observed if we have the entire population of the diabetic patients examined/screened. The association of random blood glucose with peripheral neuropathy needs to be interpreted with caution. This was an on-the-spot relationship and there is no evidence that their blood glucose at different moments were consistently so. This information would have been available to us if we were able to do the glycosylated haemoglobin (HbA1c) test. Also the observation that there were no patients with blisters, ingrown toenail, active ulcers, fixed joint and previous amputations should not be taken as though this is the true picture of patients with diabetes from Nigeria. In an evaluation of 16 French Diabetology Centres, 105 $(15.8 \%)$ of the patients had an active ulcer, $7.2 \%$ had a history of foot ulcer or lower-limb amputation, while foot deformities were found in $21.1 \%$ of the patients ${ }^{[15]}$. We do not have the entire reasons for the lack of presentation of these particular foot disorders in this present study. However, considering the fact that these problems have direct bearing with 
ambulation of the patients, it may just be possible that these individuals were not able to make it to the venue of the screening due to the peculiar transportation system in a developing country like Nigeria, which may not be in the favour of persons who have one or two disabilities. In spite of the weaknesses however, a major strength of this study is that the patients screened were those seen and managed regularly at different hospitals including both private and government owned who converged at the venue of the World Diabetes Day. This gave a much needed mix of participants rather than what would have been done only within one or two hospitals.

This one day screening of diabetic patients has revealed that sizeable number of the patients presented with foot deformities, maceration, thick planter calluses and peripheral neuropathy. Peripheral neuropathy was significantly linked with glycaemic control but not with age, duration of diabetes diagnosis or body weight of the patients. Based on the outcome of this study, it is anticipated that the assessment will continue annually as an integral part of the World Diabetes Day. By so doing, it will be fairly certain that some of the patients will have for themselves a comprehensive foot screening at least once in a year. As previously observed by the authors ${ }^{[19]}$ that accurate screening and onward referral will ensure that people with diabetes can gain access to the right care at the right time, and ultimately reduce their risk of developing foot complications. Activities like this on a world Diabetes Day celebration can go a long way in contributing towards this gesture.

\section{Acknowledgement}

The authors sincerely appreciate the members and executive committee members of the Diabetes Association of Nigeria, Ibadan Chapter for their support in carrying out this study.

\section{Conflicting interests}

The authors hereby declare no conflicting interests.

\section{References}

[1] van Schie CHM, Vermigli C, Carrington AI, Boulton A. Muscle weakness and foot deformities in diabetes: Relationship to neuropathy and foot ulceration in Caucasian diabetic men. Diabetes Care. 2004; 27: 1668-1673. PMid:15220244 http://dx.doi.org/10.2337/diacare.27.7.1668

[2] Sibbald RG, Ayello EA, Alavi A, Ostrow B, Lowe J, Botros M, Goodman L, Woo K, Smart H. Screening for the High-Risk Diabetic Foot: A 60-Second Tool (2012)(C. Adv Skin Wound Care. 2012; 25: 465-476. PMid:22990344 http://dx.doi.org/10.1097/01.ASW.0000421460.21773.7b

[3] Sutherland JE, Hoehns JD, O'Donnell B, Wiblin RT. Diabetes management quality improvement in a family practice residency program. J Am Board Fam Pract. 2001; 14: 243-251. PMid:11458966

[4] Abbott CA, Garrow AP, Carrington AI, Morris J, van Ross ER, AJ Boulton. Foot ulcer risk is lower in South-Asian and African-Caribbean compared with European diabetic patients in the U.K. Diabetes Care. 2005; 28: 1869-1875. PMid:16043725 http://dx.doi.org/10.2337/diacare.28.8.1869

[5] Boike AM, Hall JO. A practical guide for examining and treating the diabetic foot. Cleve Clin J Med. 2002; 69: $342-348$. PMid:11996205 http://dx.doi.org/10.3949/ccjm.69.4.342

[6] American Diabetes Association. Standards of medical care in diabetes -2010. Diabetes Care. 2010; 33: S11-S61. PMid:20042772 http://dx.doi.org/10.2337/dc10-S011

[7] Sibbald R, Woo K, Ostrow B. Preventing amputations: the need for screening, diagnosis and treatment of diabetic foot complications in Guyana, South America. Journal of World Council of Enterostomal Therapists. 2008; 28: 34-36.

[8] WHO. http://www.who.int/mediacentre/events/annual/world_diabetes_day/en/index.html Accessed 21 October, 2012 at 6.22 pm.

[9] Inlow S. A 60 second foot exam for people with diabetes. Wound Care Canada. 2004; 2: 10-11.

[10] Ostrow B, Woo KY, Sibbald RG. The Guyana diabetic foot project: Reducing amputations and improving diabetes care in Guyana, South America. Journal of World Council of Enterostomal Therapists. 2010; 30: 28-32.

[11] Lavery LA, Armstrong DG, Wunderlich RP, Tredwell J, Boulton AJM. Predictive value of foot pressure assessment as part of a population-based Diabetes Disease Management Program. Diabetes Care. 2003; 26: 1069-1073. PMid:12663575 http://dx.doi.org/10.2337/diacare.26.4.1069 
[12] Lázaro-Martínez JL, García-Morales EA, Aragón-Sánchez FJ, Año-Vidales P, Allas-Aguado S, García-Alvarez Y. Reducing skin maceration in exudative diabetic foot ulcers. Rev Enferm. 2010; 33: 9-14. PMid:20429204

[13] Davies M, Brophy S, Williams R, Taylor A. The prevalence, severity, and impact of painful diabetic peripheral neuropathy in type 2 diabetes. Diabetes Care. 2006; 29: 1518-1522. PMid:16801572 http://dx.doi.org/10.2337/dc05-2228

[14] Cheng YJ, Gregg EW, Kahn HS, Williams DE, Rekeneire ND, Narayan KMV. Peripheral insensate neuropathy—a tall problem for US adults? Am J Epidemiol. 2006; 164: 873-880. PMid:16905646 http://dx.doi.org/10.1093/aje/kwj281

[15] Malgrange D, Richard JL, Leymarie F, French Working Group On The Diabetic Foot. Screening diabetic patients at risk for foot ulceration. a multi-centre hospital-based study in France. Diabetes Metab. 2003; 29: 261-268. http://dx.doi.org/10.1016/S1262-3636(07)70035-6

[16] Gregg EW, Sorlie P, Paulose-Ram R, Gu Q, Eberhardt M, Wolz M, Burt V, Curtin L, Engelgau M, Geiss L. Prevalence of lower extremity disease in the US adult population $\geq 40$ years of age with and without diabetes: 1999-2000 National Health and Nutrition Examination Survey. Diabetes Care. 2004; 27: 1591-1597. PMid:15220233 http://dx.doi.org/10.2337/diacare.27.7.1591

[17] Ziegler D, Rathmann W, Dickhaus T, Meisinger C, Mielck A. For the KORA Study Group: Prevalence of polyneuropathy in pre-diabetes and diabetes is associated with abdominal obesity and macroangiopathy. Diabetes Care. 2008; 31: 464-469. PMid:18039804 http://dx.doi.org/10.2337/dc07-1796

[18] Charles M, Ejskjaer N, Witte DR, Borch-Johnsen K, Lauritzen T, Sandbaek A. Prevalence of neuropathy and peripheral arterial disease and the impact of treatment in people with screen-detected type 2 diabetes. Diabetes Care. 2011; 34: $2244-2249$. PMid:21816977 http://dx.doi.org/10.2337/dc11-0903

[19] Adejumo PO, Fasanmade A, Adeniyi A, Ilesanmi RE. The outcome of 60-second foot screening tool education for healthcare workers at University College Hospital, Nigeria. Wound Healing Southern Africa. 2012; 5(2): 91-95. 